\title{
NOT BUSINESS AS USUAL MEGA-TRENDS AND THE NEED FOR NEW CITY BUILDING APPROACHES IN THE PEOPLE'S REPUBLIC OF CHINA
}

Douglas Webster, Hubert Jenny, and Jianming Cai

NO. 26

\section{ADB EAST ASIA WORKING PAPER SERIES}


ADB East Asia Working Paper Series

\section{Not Business as Usual: Mega-Trends and the Need for New City Building Approaches in the People's Republic of China}

Douglas Webster, Hubert Jenny, and Jianming Cai

No. 26 | February 2020
Douglas Webster is a professor on East Asian Urbanization at the Arizona State University. Hubert Jenny is a principal infrastructure finance specialist for the East Asia Department at the Asian Development Bank. Jianming Cai is a professor for the Institute of Geographical Sciences and Natural Resources Research at the Chinese Academy of Sciences. 
(C) 2020 Asian Development Bank

6 ADB Avenue, Mandaluyong City, 1550 Metro Manila, Philippines

Tel +6328632 4444; Fax +63286362444

www.adb.org

Some rights reserved. Published in 2020.

Printed in the Philippines

Publication Stock No. WPS200060-2

DOI: http://dx.doi.org/10.22617/WPS200060-2

The views expressed in this publication are those of the authors and do not necessarily reflect the views and policies of the Asian Development Bank (ADB) or its Board of Governors or the governments they represent.

ADB does not guarantee the accuracy of the data included in this publication and accepts no responsibility for any consequence of their use. The mention of specific companies or products of manufacturers does not imply that they are endorsed or recommended by ADB in preference to others of a similar nature that are not mentioned.

By making any designation of or reference to a particular territory or geographic area, or by using the term "country" in this document, $A D B$ does not intend to make any judgments as to the legal or other status of any territory or area.

This work is available under the Creative Commons Attribution 3.0 IGO license (CC BY 3.0 IGO)

https://creativecommons.org/licenses/by/3.0/igo/. By using the content of this publication, you agree to be bound by the terms of this license. For attribution, translations, adaptations, and permissions, please read the provisions and terms of use at https://www.adb.org/terms-use\#openaccess.

This CC license does not apply to non-ADB copyright materials in this publication. If the material is attributed to another source, please contact the copyright owner or publisher of that source for permission to reproduce it. $A D B$ cannot be held liable for any claims that arise as a result of your use of the material.

Please contact pubsmarketing@adb.org if you have questions or comments with respect to content, or if you wish to obtain copyright permission for your intended use that does not fall within these terms, or for permission to use the ADB logo.

Corrigenda to ADB publications may be found at http://www.adb.org/publications/corrigenda.

Notes:

In this publication, "\$” refers to United States dollars and "CNY” to yuan.

ADB recognizes "China” as the People's Republic of China.

The ADB East Asia Working Paper Series is a forum for stimulating discussion and eliciting feedback on ongoing and recently completed research and policy studies undertaken by the East Asia Department of the Asian Development Bank (ADB) staff, consultants, or resource persons. The series deals with key economic and development problems, as well as conceptual, analytical, or methodological issues relating to project/program economic analysis, and statistical data and measurement. The series aims to enhance the knowledge on Asia's development and policy challenges; strengthen analytical rigor and quality of ADB's country partnership strategies, and its subregional and country operations; and improve the quality and availability of statistical data and development indicators for monitoring development effectiveness.

The ADB East Asia Working Paper Series is a quick-disseminating, informal publication whose titles could subsequently be revised for publication as articles in professional journals or chapters in books. The series is maintained by the East Asia Department.

This paper was prepared as a background study for the preparation of the High-Level Round Table Discussion on the transition of the People's Republic of China to high-quality development, coordinated by the Asian Development Bank. 


\section{CONTENTS}

TABLES AND FIGURES Iv

ACKNOWLEDGMENTS V v v v v v

ABSTRACT - vi

ABBREVIATIONS vii

I. THE DRAMATIC MEGA-TRENDS SHAPING URBANIZATION AND CITY BUILDING 1

A. Demographic Trends $\quad 1$

B. Changes in Economic Structure and Growth Rates 2

C. Changing Social and Consumption Preferences 3

D. Climate Change 4

E. Changing Urban Technologies $\quad 4$

F. Changing Rural Context 5

II. THE EVOLVING URBAN SYSTEM IN THE PEOPLE'S REPUBLIC OF CHINA 6

A. Continued Dominance of the Eastern Coastal Region 6

B. Urban Clusters 8

III. IMPLICATIONS OF MEGA-TRENDS: ISSUE AREAS AND IMPLICATIONS 10

A. Urban Population Decline 11

B. Shaping a More Rational Urban System 12

C. Shaping Future Metropolitan Structure $\quad 16$

D. Pivoting to Quality Urban Regions

E. Urban Fiscal Sustainability 23

$\begin{array}{ll}\text { IV. OVERALL STRATEGY THRUSTS } & 25\end{array}$

APPENDIX

1. Lead Urban Policies: 13th National Development Plan and New Urbanization Policy 26

2. Cluster Region Parameters (Population) 27

3. Cluster Region Parameters, Ranked by GDP per Capita 28

4. Cluster Region Parameters (Built-up Land) 29

$\begin{array}{ll}\text { REFERENCES } & 30\end{array}$ 


\section{TABLES AND FIGURES}

\section{TABLES}

1 Urban Population Increment Forecast in the PRC: 2020-2050 1

2 Rural Population and Change by 5-Year Increment Forecast in the PRC: 2020-2050 2

\section{FIGURES}

1 Population Growth Rates by Policy Regions: 1990-2000 and 2000-2010 6

2 Population Forecast to 2030, Major Cities 7

3 GDP Change by Province in the PRC, 2014-2018 7

4 Nineteen Urban Clusters Identified in the National 13th FYP 9

5 San Francisco Zoning Allows Kaleidoscope Structure: Multiple Uses in One Block 17

6 Stock of Government Investments in Fixed Assets 23 


\section{ACKNOWLEDGMENTS}

This paper was prepared for the High-Level Round Table Discussion on the transition of the People's Republic of China to high-quality development, coordinated by the Asian Development Bank. It incorporates participants' comments from that event on 5 November 2018, and a roundtable discussion with technical experts on 5 July 2019. The authors acknowledge the research assistance of Jianyi Li. 


\begin{abstract}
This paper assesses the urban future of the People's Republic of China (PRC), currently home to 59\% of the national population, from the perspective of mega-trends that are dramatically affecting the country. These mega-trends include: (i) urban demographic decline and aging; (ii) changes in the structure of urban economies with the shift to a more innovation and consumer-oriented economy; (iii) shifts in consumer preferences, such as the increased desire of Chinese people (particularly millennials) to live in high amenity cities and neighborhoods; (iv) climate change; (v) technological innovation related to smart cities and autonomous vehicles; and (vi) the changing rural context.

These drivers will interact with the contemporary Chinese urban system over the medium-term and beyond. It will not be business as usual for Chinese city building; new urban policies, approaches, and technologies will be necessary.

The paper examines the implications of the intersection of powerful mega-trends and urban processes. It advocates: (i) urban development that responds to realistic urban demographic forecasting to avoid "over-shoot" in city building and infrastructure investment; (ii) an overall shift in the focus of urban development from quantity to quality; (iii) compact, land efficient, and land use planning to improve the green performance and livability of Chinese cities; (iv) reform of urban fiscal mechanisms to reduce the importance of land lease sales under the current model; ( $v$ ) improvement in the efficiency of metropolitan and urban cluster labor markets to accelerate innovation and economic growth; (vi) new policies and mechanisms to strengthen urban clusters; and (vii) major changes in land use and construction standards to enable city building that supports innovation and quality through such means as more mixed land use; more compact, higher ground coverage mid-rise development; new types of zoning; and new approaches to green space configuration. These strategies are important to help the PRC pursue its goal of ecological civilization with greater harmony between humans and nature in a low carbon and more inclusive economy.
\end{abstract}

Keywords: urban development, the People's Republic of China, hukou, fiscal sustainability, "New Chinese Cities", urban clusters, metropolitan structure, urban system, land efficiency, community livability. 


\title{
ABBREVIATIONS
}

\author{
ADB Asian Development Bank \\ GBR Greater Bay Region \\ GDP gross domestic product \\ EDTZ economic and technology development zone \\ FAR floor area ratio \\ HSR high-speed rail \\ PPP public-private partnership \\ PRC People's Republic of China \\ TOD transit oriented development \\ US United States
}





\section{THE DRAMATIC MEGA-TRENDS SHAPING URBANIZATION AND CITY BUILDING}

The PRC is going through more dramatic socio-economic change than at any time since 1949. Given that the PRC's urban areas are home to the majority of its people (59\%) and generate the overwhelming majority of its economy (over $80 \%$ ), current changes and stresses are manifest strongly in urban areas. In this section, we discuss key mega-trends that will shape the PRC's urban future. How the government and the private sector respond to them will be critical in shaping the PRC's future as it pursues a better life (meihaoshenghuo) for its people under the ecological civilization paradigm. ${ }^{1}$

\section{A. Demographic Trends}

A very important mega-trend affecting cities will be a dramatic change in the PRC's demography. ${ }^{2}$ As of mid-year 2018, there are 837 million urban residents and 578 million rural residents. Urbanization has been increasing by about 1 percentage point per year, on average, over the last decade. ${ }^{3}$ The PRC was an early and rare adopter of a "pro urbanization" policy, especially among developing countries, in the 1980s. That policy, along with export-led industrialization, accounts for much of the country's economic success and its historically unprecedented decline in absolute poverty. Early economic gains from urbanization were very large and relatively easy to achieve. For example, a farmer from rural PRC might increase his/her income by 2-3 times in one week by moving to a city, such as Shenzhen, where factory jobs were abundant. Migration flows were very large at the height of the rural-urban transition in the late 20th and early 21 st centuries.

However, the rate of urbanization is forecast to start dropping significantly in the next decade. The PRC's "floating" population (rural-urban migrants living in cities) now numbers close to 300 million people, but will grow slowly going forward. Between 2008 and 2018, the PRC added 211 million urban residents, mostly as a result of net migration. Between 2020 and 2030 (which includes the medium-term period) the urban population is forecast to increase by a much lower 142.8 million, mostly as a result of net domestic migration. Between 2030 and 2040, the PRC will only add 65.6 million urban residents and by 2045-2050, the urban population will start to absolutely decline. (See Table 1).

Table 1: Urban Population Increment Forecast in the PRC: 2020-2050 (thousand)

\begin{tabular}{cc}
\hline Period & Increment \\
\hline $2020-2025$ & 81,478 \\
$2025-2030$ & 61,294 \\
$2030-2035$ & 41,771 \\
$2035-2040$ & 23,845 \\
$2040-2045$ & 8,573 \\
$2045-2050$ & -89 \\
\hline
\end{tabular}

Note: For statistical purposes, the data for the People's Republic of China (PRC) do not include Hong Kong, China; Macau, China; and Taipei,China.

Source: United Nations, Department of Economic and Social Affairs, Population Division. 2018.

\footnotetext{
Harmony between human and nature resulting in a low carbon economy.

2 Fortunately, demography can be forecast more easily than other developmental parameters. Most people who will live in the PRC in 30 years time, have already been born.

3 Data source: UN, World Urbanization Prospects 2018, New York: UN Population Division, 2018. The 2019 version of this report will be released on June 18, 2019.

4 The term is a misnomer. Migrants tend to stay in the city that they migrate to, not float among cities.
} 
As indicated by Table 2, the PRC's rural population has been declining in absolute terms since 1995, and will continue to do so for the foreseeable future. However, as indicated by Table 2, the magnitude of the decline in the rural population will continue to decrease, simply because so many of those who wish to leave rural areas have already done so.

Table 2: Rural Population and Change by 5-Year Increment Forecast in the PRC: 2020-2050

\begin{tabular}{ccc}
\multicolumn{3}{c}{ (thousands) } \\
\hline Year & Population & Change \\
\hline 2020 & 549,472 & \\
2025 & 482,282 & $-67,190$ \\
2030 & 423,334 & $-58,948$ \\
2035 & 373,890 & $-49,444$ \\
2040 & 334,009 & $-39,881$ \\
2045 & 302,324 & $-31,685$ \\
2050 & 272,509 & $-29,815$ \\
\hline
\end{tabular}

Note: For statistical purposes, the data for the People's Republic of China (PRC) do not include Hong Kong, China; Macau, China; and Taipei,China.

Source: United Nations, Department of Economic and Social Affairs, Population Division. 2018.

Economists argue that the "Lewis Tipping Point" may be reached soon, that is, where surplus rural labor is no longer readily available in large numbers. Not only is the number of rural residents declining absolutely, and thus the potential rural-urban migrant flow, but the rural population is aging, and thus less likely to migrate. The recently instituted rural vitalization policy supports agricultural modernization and could speed out-migration from rural areas if the experience of similar programs in East and Southeast Asia holds. Rural revitalization in many Asian countries triggers growth in per capita income and economic modernization. A side-effect is often rural depopulation, associated with more efficient agriculture and rural enterprises and greater connectivity with cities.

The PRC is forecast to reach the "normal" developed country urbanization level of $80 \%$ in the 20452050 period (78.3\% in 2045 and 80\% in 2050 according to United Nations (2018)). By 2025, the urbanization level is forecast to be in the range of $66.5 \%$ (United Nations 2018).

\section{B. Changes in Economic Structure and Growth Rates}

The second key mega-trend affecting urbanization and city building is the slowing of economic growth and dramatic changes to the structure of urban economies.

The PRC experienced a well-earned span of unprecedented high annual economic growth of 10\% or higher beginning with the opening up of the 1980s and lasting until 2010, when growth dropped below $10 \%$. Most urban areas grew even faster than the national economic rate over the last four decades. However, there is a consensus, both in the PRC and internationally, that growth will likely continue to decline from the current $6.4 \%$ annual rate. A future mid-term growth rate of $5 \%$ would be regarded as outstanding performance for an upper-middle income country. Urban regions may grow somewhat faster than the national rate, although the gap between rural and urban economic growth rates is expected to 
narrow as the PRC becomes dominantly urban, especially if rural vitalization is effective. This slowing in economic growth will have implications for urban places, both positive (allowing time to catch up with environmental improvements) and negative (such as slower growth in fiscal resources and slower household income growth).

Changes in the urban economic structure will be very important. It is well known that the PRC's competitiveness in routine export-oriented manufacturing is eroding, especially in coastal areas. At the same time, the government, and its ever more well-educated populace, are increasingly pursuing an innovation economy. In parallel, policy increasingly supports consumption as reflected in higher demand for a growing array of personal services and high-end goods. These factors have a strong impact on both the economic and physical structure of the PRC cities. As the high-end service sector (both business/ producer and personal services) becomes increasingly important relative to manufacturing, centripetal (core centered) spatial development forces are becoming stronger in the PRC's urban regions. In essence, increased activity will take place in innovation zones, co-shared workspace complexes, and lifestyle districts. This is very different from the strong centrifugal forces that dominated metropolitan development as manifest in gigantic manufacturing ("factory of the world") peri-urban manufacturing zones in the late 20th century and early 21st century. These manufacturing driven peri-urban areas tended to be 25-100 (or more) kilometers from the core city.

\section{Changing Social and Consumption Preferences}

One of the key shapers of the PRC's future urbanization and city building will be the changing preferences of Chinese residents in regard to where they want to live, and in what types of urban environments they prefer to live and work. Such change will be rapid, driven by high use of social media. Consumer preferences that dramatically affect the urban system are expressed through the housing market, migration behavior, and job selection. Of course, such choices are made in the context of supply (for example, housing products offered by developers), policies that affect migration (hukou and portability of social benefits), and the employment market.

Researchers have noted three key changes in urban living preferences in the PRC. First, as people become more affluent, they are more sensitive to amenities (essentially the attractiveness of a place) in choosing cities, regions, and/or neighborhoods within which to reside, work, or live part of the year. Climate is the biggest factor in terms of amenity migration, but scenery and environmental quality are also strong pulls. The strength of this driver cannot be over-estimated. In the United States (US), about $40 \%$ of the population shifted in an 80-year period to the Sun Belt. ${ }^{5}$ Such dynamics are starting in the PRC, particularly shifts from the Northeast to warm cities such as Sanya, often on a seasonal basis. This movement to amenity is likely to accelerate, with cities such as Qingdao, Kunming, Shanghai, Sanya, Xiamen, and Hangzhou attracting people in search of a better climate and quality of life.

The second change is the quest for quality in housing and neighborhoods. The PRC has succeeded quantitatively, producing enough (in some cases, too much) housing and urban infrastructure. However, quality at the housing unit, building, and community level is often lacking. This applies to the quality of construction (including energy efficiency of buildings), urban design, siting of local facilities (schools, and medical facilities) at both neighborhood and metropolitan scales, and local accessibility, including walkability. Better urban design in residential neighborhoods would include improved siting, spacing, size, height, and spatial configuration of buildings; amenities on land surrounding buildings; better access to transit stops: and less fencing and gating.

$5 \quad$ The US industrial Mid-West declined from 31\% of the US population in 1930 to $28 \%$ in 1970 and 22\% in 2010. The northeast, declined from $28 \%$ of the population in 1930 to $24 \%$ in 1970 , and $22 \%$ in 2010 . Meanwhile, the proportion of the south and west regions of the US population rose from 41\% in 1930 to 48\% in 1970, and 60\% in 2010. 
Increasingly affluent urban residents desire higher quality metropolitan environments. Prime expectations are for: (i) higher air quality, as indicated by the volume of social media discussion on this topic, (ii) cleaner surface water, (iii) accessible and usable public spaces, especially "third places" and green space, and (iv) reduced natural hazard risks, such as flooding.

Third, the millennial generation will soon be the largest component of the labor force. Like preceding generations, they will prefer to live in core cities. The PRC millennials are more likely to work in the service sector than their predecessors, including in innovation and creative fields. They increasingly express preferences to live in lively 24/7, mixed use (both horizontal and vertical) living environments.

\section{Climate Change}

Climate change is discussed in an accompanying paper (Hanson 2019). Rapid urbanization continues to feed increased greenhouse gas emissions. Urban areas are also particularly exposed to the adverse impacts of climate change-including intensified flooding, heat waves, and water supply shortagesdue to the high concentrations of residents, infrastructure, and fixed assets. Climate change will affect the PRC's urban development in several ways. First, coastal areas may be threatened by sea level rise and off-sea storms. For example, the Binhai New City in Tianjin, which is covers 2,270 square kilometer and is home to approximately three million people, is at or below sea level. Second, warmer climates and rainfall patterns may move northward, changing agricultural systems, worsening water supply issues in some cities, altering natural disaster risk patterns, and changing amenity migration dynamics.

Cities are key in the PRC's paradigm shift towards ecological civilization. Since the first climate change action was set as a national goal in 2009, the PRC's cities have implemented policies and programs such as eco-cities, low carbon pilot cities, and sponge cities. The national government has committed to peak carbon emissions by 2030, and a large number of cities have already pledged to meet this commitment around or before the national deadline. Most cities, especially in northern PRC, are faced with limited water resources, and competitive use of water is heightened by climate change. The result is a waterfood-energy nexus with water as a limiting factor for growth.

\section{E. Changing Urban Technologies}

Rapid, world-wide change is underway in the development and deployment of new or improved urban technologies. Accordingly, urban policy makers and city builders need to incorporate appropriate new technologies into the future design of cities. Experience indicates that such innovation should be implemented in a customized fashion for each city, rather than through development of comprehensive smart cities. Deployment of new urban technologies is especially important in the PRC, given its innovation oriented economy. Products resulting from new technologies such as smart urban rapid transit systems can be exported, as is already occurring, for example, to Bangkok. Particularly important are urban technology innovations in such areas as (i) smart cities based on monitoring and advanced software; (ii) autonomous and alternative fuel vehicles; (iii) new land-use planning and management systems, such as form based zoning; (iv) new communication technologies such as 5G; (v) new types of high-speed public transit such as next generation HSR; (vi) new types of flood control and drainage technologies such as sponge cities; (vii) cleaner, more energy efficient manufacturing processes; and (viii) more energy efficient buildings. 


\section{F. Changing Rural Context}

The urban built up area of the PRC covers 1.52\% of the PRC's land area; thus, urban land cover is insignificant in a direct quantitative sense. ${ }^{6}$ However, only $13 \%$ of the PRC's land is arable, and urban areas are frequently located on the most fertile land; for example, in deltas such as Guangzhou or on agriculture plains such as Chengdu. With the decline in the rural population, most of the interior land area of the PRC is being depopulated, in common with many other continental-sized countries, while modernization of agriculture is likely to reduce the land area needed to ensure overall food security. With $80 \%$ of the PRC's population soon to live in cities, urban pressures will be exerted on rural areas, especially those near cities. Increasingly affluent cities will demand high quality food (especially fruits, vegetables, and meat), ecoservices, natural resources such as water, and recreational and second home spaces. The future of the PRC's cities is highly interdependent with the future of rural areas. As such, it is critical to reduce the $60 \%$ food wastage between production and consumption by improving storage, transportation, and farmers' access to markets to guarantee a certain level of food security for Chinese cities.

\footnotetext{
Based on the research of Professor Peng Gong at Tsinghua University. Urban residents in PRC occupy 152 square meters
} per capita, 35\% higher than Japan's metric of 132 square meters per capita. 


\section{THE EVOLVING URBAN SYSTEM IN THE PEOPLE'S REPUBLIC OF CHINA}

\section{A. Continued Dominance of the Eastern Coastal Region}

Figure 1 indicates that the eastern coastal region of the PRC was by far the fastest growing region in both the 1990-2000 and 2000-2010 inter-census periods. In other words, policy attempts to re-orient the geographic focus of demographic growth to the interior and west from the east coast have had limited success. This is due to the overwhelming momentum and advantages of the PRC's cosmopolitan east coast region, driven by the Pearl River Delta or Greater Bay Area, West Strait, Yangtze River Delta, and Beijing-Tianjin-Hebei urban clusters. This trend continues driven by strong market forces, and increasingly by amenity drivers. Despite the movement of non-competitive manufacturing from the coast to the Interior (Webster et al. 2012; Webster et al. 2013; Li, Webster and Cai 2018), as indicated by Figure 2, official forecasts (United Nations 2018) indicate that all the fastest growing cities in the PRC will continue to be located along the east coast.

Figure 1: Population Growth Rates by Policy Regions: 1990-2000 and 2000-2010

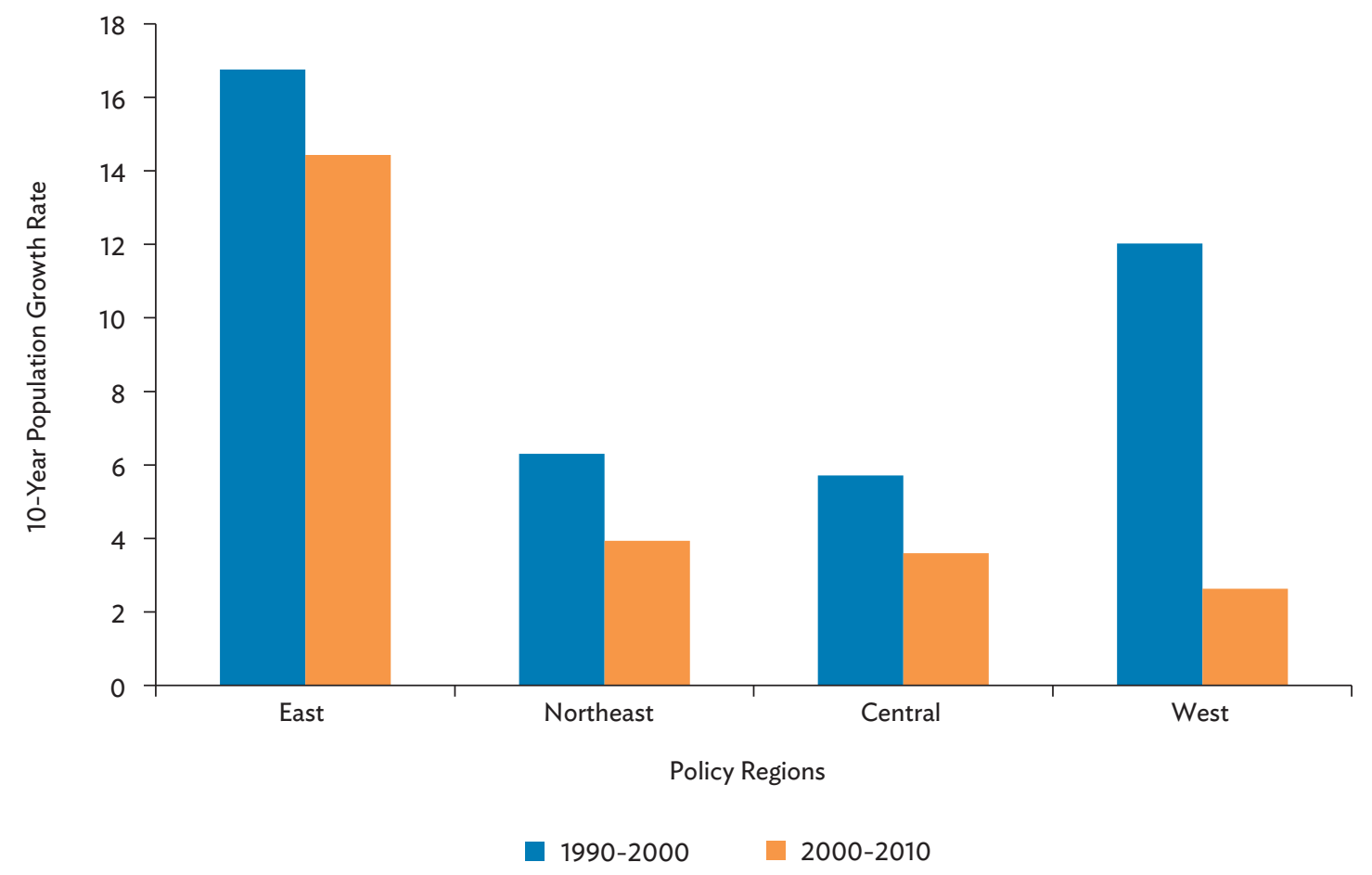

Source: Webster et al. (2012).

Per capita GDP is also increasing faster on the east coast (The Economist, 2019).See Figure 3. Fiscal deficits have remained low, rising from $2 \%$ in 2000 to 3.9\% (2018) in contrast to a concerning expansion from 5.5\% to $15.5 \%$ in western and central PRC over the same time period. The western and central regions are also more dependent on public investment than the coastal region: 68\% of regional GDP in the west and $60 \%$ in central PRC comes from public investment, compared with $43 \%$ in the south (2019). 

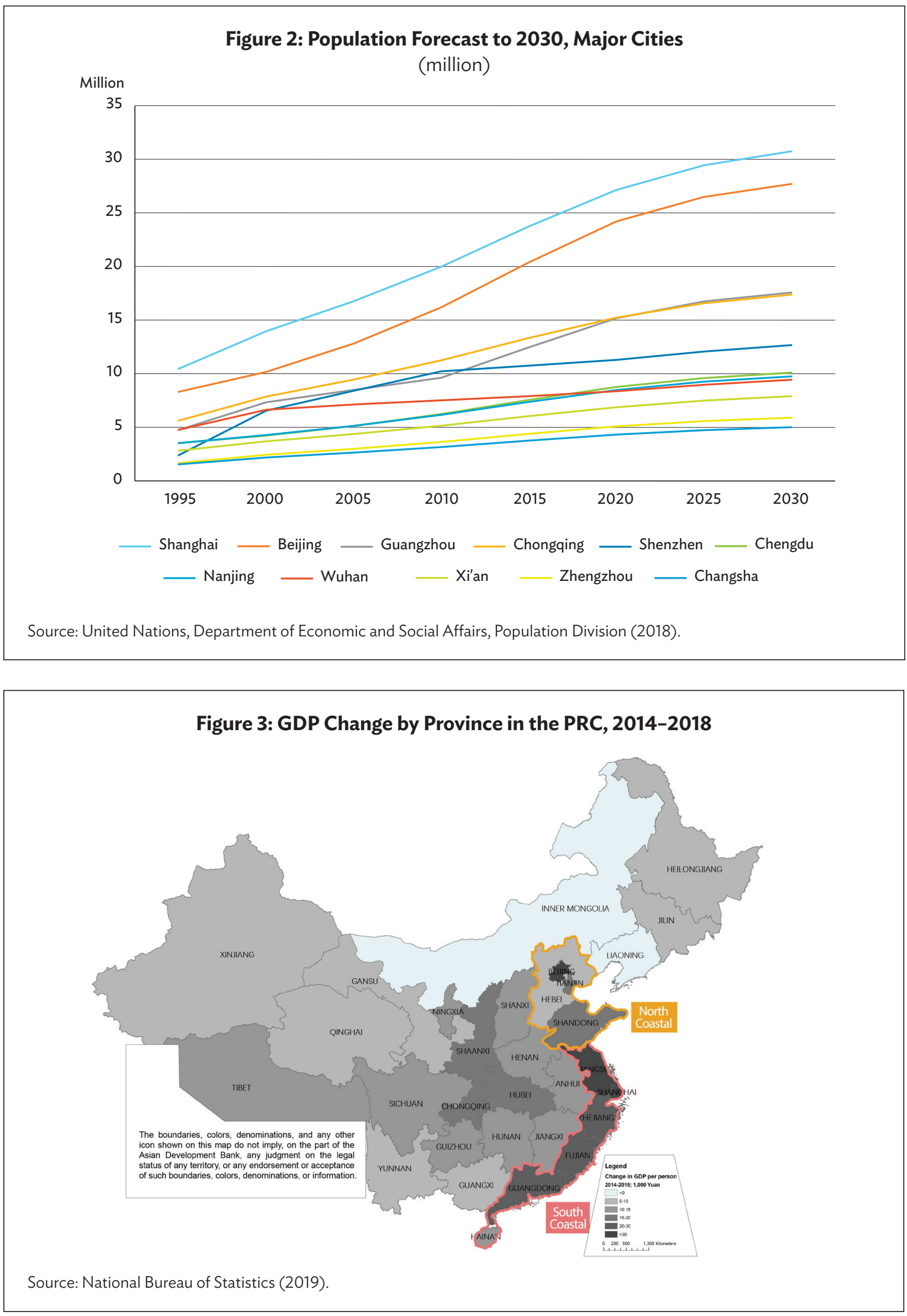
This rise of superstar regions and cities in the PRC is not unexpected-similar dynamics are welldocumented in research on the urban systems and economic geography of the US and Europe. Attempts to reorient economic and demographic growth to interior PRC may therefore face headwinds from the momentum and advantages embedded in the east coast clusters.

\section{B. Urban Clusters}

The PRC's urban population is not spread evenly across the country; rather, it is concentrated around a limited number of dominant centers. The urban population, like the overall population, is highly skewed toward the eastern half of the country. Figure 4 describes 19 urban clusters that have been identified by urban analysts in the PRC and officially adopted in the $13^{\text {th }}$ Five Year Plan (FYP). ${ }^{7}$ The 19 clusters are geographically large (perhaps defined too broadly), and account for $29.59 \%$ of the PRC's land area. Unlike the US, for historical reasons, PRC's major urban agglomerations tend to be constellations, diffusing out from major centers, rather than corridor based. ${ }^{8}$ To the extent that urbanization is corridor based, it is particularly along rivers (the Yangtze and Yellow Rivers) and secondarily along historical main railway routes. Within the PRC's urban clusters are all types of urban settlements from cities proper (generally contiguous urban districts constituting urban cores of large cities) containing over 10 million people to mid-sized cities, county cities, towns, villages and rural areas. Thus, it is misleading to think of the PRC's urban clusters as very large, spread-out urban areas; rather, they are inter-connected regional sets of different sized settlements, with large interstitial rural areas. Rural areas constitute the majority of the land area within urban clusters.

Most economic and human activity occurs in the urban clusters. In 2016, 82.8\% of the PRC's population lived in the urban clusters, up from $82.61 \%$ in 2012. Urban clusters accounted for $89.81 \%$ of the built up land in 2016, up from $88.81 \%$ in 2012; and most strikingly, they accounted for $90.53 \%$ of the PRC's GDP in 2016, albeit down from $93.91 \%$ in 2012.

Chinese urban clusters tend to be very large in population, as well as in area. For example, the Yangtze River Delta Cluster had a population of 152 million people in 2016, making it the largest true megapolitan region in the world by population. (The Central Plain and Mid-Yangtze River Clusters in the PRC have even larger populations but are not real urban clusters in the sense of connectedness. See Appendix 2 for demographic data on Chinese urban clusters). By comparison, the Blue Banana urban cluster in Europe, stretching from Manchester to Milan contains over 100 million people, while the Mid-Atlantic (or Northeast Megapolis) urban cluster along the mideastern coast of the US, running in areas from Boston to Washington, DC, contains over 60 million people. The Great Lakes Mega-Region in North America straddling the CanadaUS border contains more people than the northeast megapolis but is less important in terms of global role and profile. The Tokaido megalopolis, running from Tokyo to Osaka contains about 84 million people. These four international clusters are also the wealthiest urban megapolitan agglomerations in the world, benefiting from their location in advanced economies and from very significant agglomeration and cluster economies, including substantial benefits from large, efficient labor markets.

7 Chinese urban clusters have been essentially defined based on the international definition of mega-urban areas. According to this definition, a cluster must contain at least two metropolitan areas of at least 2 million each in population, the total population of the cluster must exceed 10 million, and there must be substantial linkages (connectivity) among places in the cluster. The latter should not be confused with commuting (or commuter sheds), a metric applicable to the metropolitan scale. Thus, connectivity in an urban cluster might involve purchase of high-end services, such as advertising in Beijing by a firm from Tianjin, firm supply chains between Hangzhou and Ningbo, university catchment areas.

8 Historically, until recently (with the construction of the modern infrastructure system after 1980), PRC's cities were poorly connected and the national economy was weakly linked. For centuries, under the Imperial Kingdom, regional cities would dominate, enjoying considerable autonomy. ("The mountains are high and the emperor is far away"). These dominant cities tend to be provincial capitals today. Even in the late 20th century there was considerable protectionism in products and labor across provinces, which can be perceived as hinterlands of dominant historical regional power centers. For further discussion of the Chinese urban constellation concept see Webster et al. (2013). 


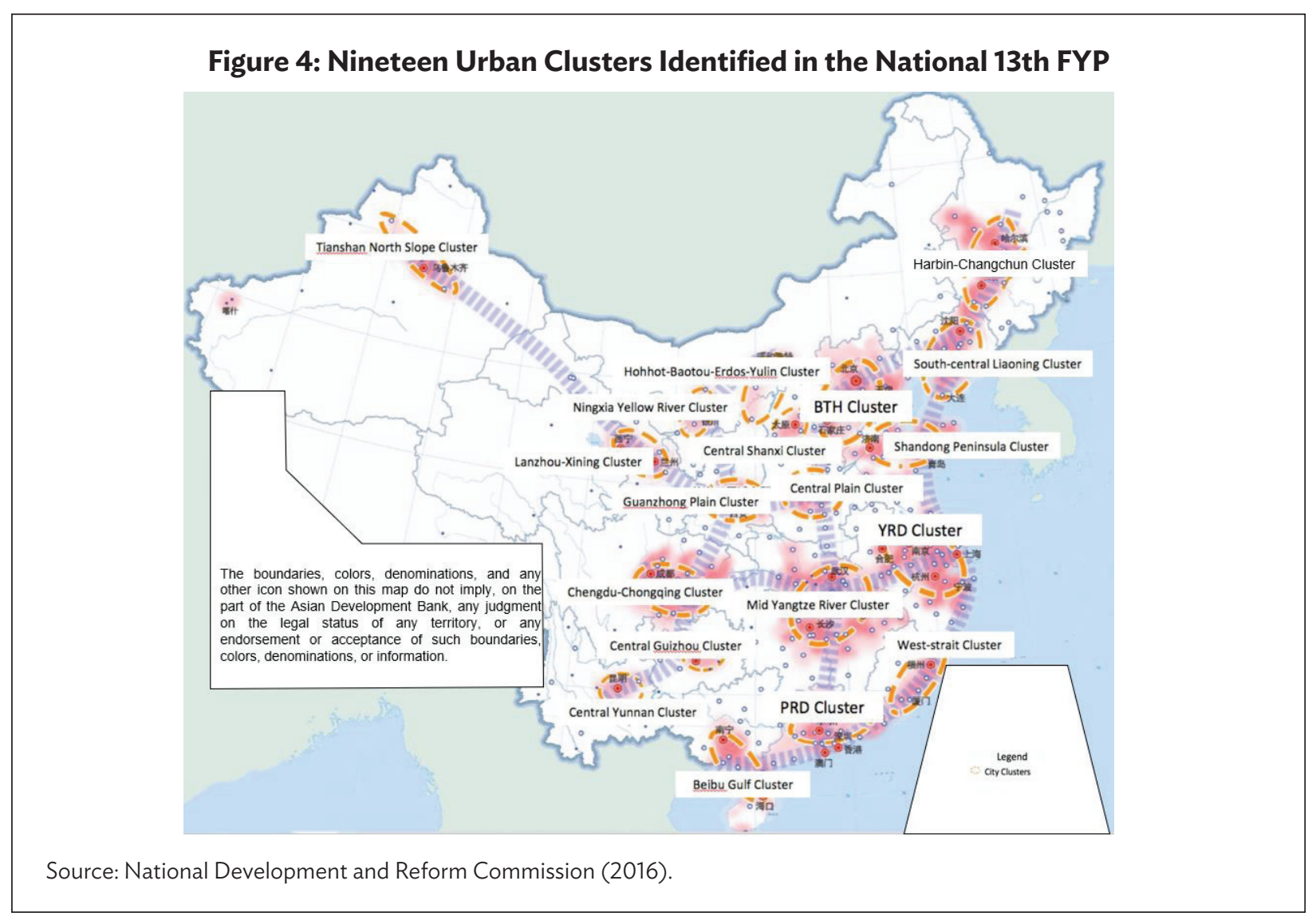

Although some Chinese analysts are concerned about the overwhelmingly large population and economies of the leading urban clusters, the three leading Chinese megaregions (Beijing-Tianjin-Hebei, Yangtze River Delta, Pearl River Delta) are actually less dominant in terms of proportion of population and economy relative to national systems than the three leading mega-urban clusters in the US (BostonWashington, Chicago-Pittsburgh, San Diego-San Francisco) and the three leaders in Japan (Greater Tokyo Area, Nagoya Mega Region, Kansai Mega-Region) (Yang 2019). Because even leading Chinese urban clusters will likely be losing population late in this century, it may be counterproductive to try to control their population growth or to cap urban population. Globalization and innovation thrive in large cosmopolitan mega urban regions.

Although the PRC has defined 19 urban clusters, only six are relatively mature in terms of connectiveness: the Beijing-Tianjin-Hebei Cluster, the Yangtze River Delta Cluster, the Pearl River Delta Cluster (the dominant three Chinese urban clusters in economic terms), plus the West Straits Cluster, the Shandong Peninsula Cluster, and the South-Central Liaoning Cluster, which was the most industrialized area of the PRC from the 1930s to 1960 s. The Chengdu-Chongqing and Harbin-Changchun clusters have potential for substantial connectiveness with recent major investments in intra-cluster transportation systems, but true connectiveness to date remains limited. Recently, the Pearl River Delta Cluster has been referred to as the Greater Bay Region, and expanded to include Macau, China; and Hong Kong, China. This represents a new genre of urban cluster in the PRC. In 2018, opening the high speed rail (HSR) line connecting Guangzhou and Hong Kong, China as well as the bridge linking Hong Kong, China; and Macau, China created the potential for connectiveness that will likely make the Greater Bay Region a strongly economically integrated urban cluster. Other defined clusters display very little real functional integration and connectiveness. For example, in the Central Yangtze River Cluster, linkages are moderate between Wuhan and Changsha (an HSR connection), but Nanchang is poorly connected to Wuhan and 
Changsha. Chengdu and Chongqing, in the west may have potential for complementary development, but there is limited formal co-operation, despite recent large-scale investment in two HSR lines. The fact that Chengdu and Chongqing are 400 kilometers apart, separated by mountainous terrain, is an obvious constraint to true urban cluster formation.

In economic terms, there are large scale differences in the economic performance of the Chinese urban clusters. The Yangtze River Delta Cluster is, and will be, one of the richest megapolitan areas in the world. In terms of GDP, Shanghai metropolitan area is forecast to rank fifth and Suzhou eighteenth globally in 2035 (Oxford Economics 2019). Shenzhen, part of the Guangdong-Hong Kong, China-Macau, China Greater Bay Area (GBA) urban cluster is already one of the world's leading innovation centers; it is part of the Silicon Valley technology eco-system, specializing in prototyping; and the headquarters of several leading Chinese technology firms, such as Huawei. It is forecast to rank 11th in the world in GDP in 2035, with strong linkages to Guangzhou, which is forecast to rank 8th. However, other urban clusters are struggling; the Harbin-Changchun urban cluster lost 1.3 million people from 2012-2016, and this population decline is expected to accelerate. The Harbin-Changchun cluster is experiencing typical rust belt dynamics with deindustrialization, outmigration (especially skilled human resources, despite the presence of the prestigious Harbin Institute of Technology), and associated high local debt. As the PRC becomes more affluent, amenity challenges, such as the harsh climate, will accelerate outmigration from the Harbin-Changchun Cluster. The South-Central Liaoning Cluster is experiencing similar dynamics and challenges, with a decline in GDP of 17.3\% over the 2012 to 2016 period. (See Appendix 3 for economic data on Chinese urban clusters). Because of the similar set of policy issues, combining these two northeast clusters is being considered. However, while looking at the northeast as a single system may make sense from a policy point of view, the area is too large to plan and develop in "on the ground" terms as a single urban cluster. The Tianshan North Slope cluster is natural resource based and associated with both natural resource depletion issues and a harsh climate; it too is experiencing population decline. The Hohhot-Baotou-Erdos-Yulin Cluster and the Ningxia Yellow River Cluster are also natural resource-oriented and face economic challenges including resource depletion, possible environmental degradation, and large swings in commodity prices.

Because the Chinese urban clusters are so large in area, there is great socio-economic diversity within them, not just among large cities and smaller settlements and rural areas, butalso among large metropolitan areas within given clusters. In this respect, the Beijing-Tianjin-Hebei cluster offers a dramatic illustration. Beijing is healthy economically to the extent that it has attracted population caps, along with Shanghai. It is forecast to have the sixth largest global city GDP in 2035 (Oxford Economics 2019). In contrast, Tianjin is among the slowest growing provincial level cities in the PRC with GDP growing at only 3.5\% annually since the beginning of 2017. Part of Tianjin's problem appears to be overbuilding in the Binhai New Area, particularly the planned financial district, resulting in a waste of resources. Tianjin could redefine its long-term vision within the Beijing-Tianjin-Hebei cluster and build on its identified strengths and competitive advantages to complement and support the cluster.

\section{IMPLICATIONS OF MEGA-TRENDS: ISSUE AREAS AND IMPLICATIONS}

This section outlines what we deem to be the most pressing issues facing the PRC in terms of urbanization and city building. We do not put forward detailed recommendations, but rather attempt to point out the implications of ongoing urban dynamics. 


\section{A. Urban Population Decline}

The PRC's urban population will peak around 2045. However, population dynamics will vary widely across cities. Some cities, such as those in the northeast, are already declining demographically, while Beijing will probably remain demographically stable past mid-century (perhaps to 2065), echoing Tokyo's population trajectory in a demographically shrinking Japan. (In Japan, virtually all cities are losing population, but the population of Tokyo remains stable).

The implications of demographic slowing in the PRC's cities are enormous and require immediate attention, especially during the medium-term and beyond. This is because major physical restructuring of urban areas requires elapsed time of 15 to 20 years.

The size of the national labor force is already contracting and this trend will soon be manifest clearly in the PRC's cities, again with considerable differentiation across cities. The population in the PRC's cities is also aging with considerable variation among cities. Shenyang is aging the fastest but has a relatively young population (median: 29 years) by Chinese standards. Mature cities, such as Shanghai, are also aging quickly.

In general, Chinese cities need to revise policies to: (i) reflect that cities will start competing for population; (ii) improve the labor participation and productivity of older urban population cohorts through public health measures and retraining (Lee 2019); (iii) phase out population caps in mega metropolitan areas, such as Shanghai and Beijing, to avoid earlier than necessary demographic decline; (iv) focus more on the quality, rather than quantity, of housing, urban design, urban transport, and public facilities, and avoid over-building of infrastructure, especially in cities expected to experience significant population decline; and ( $v$ ) reform fiscal systems which are significantly based on land sales, as the demand for land is closely related to population growth. Excessive leasing of land for rural-urban conversion should be avoided. For example, the Binhai or Chongqing (Liangjiang) "New Area" cases will no longer be effective from either an economic growth or local finance perspective. It will be necessary to implement new nonland leasing-based sources of revenue such as property taxes and land value capture. The policy reforms should also avoid leap-frogging and patchy development. Inefficient spatial patterns with significant negative environmental, energy, economic efficiency, and human time impacts will be made permanent under stagnant urban population growth, with no additional population to drive corrective infilling, at both micro intra-city and macro metropolitan and urban cluster scales.

One reason for the vast over planning and allocation of land for construction in the PRC's cities is that demographic forecasts at the municipal level are almost invariably far too high. Part of this is because ambitious land leasing is needed for revenue purposes. Greater technical attention to sub-national (especially urban) demographic forecasting is needed, which may require additional training of local planning personnel. Local planners need to focus on the future demography and functions of cities (form follows function), rather than taking a primarily supply-side ("build it and they will come") approach to city planning and development.

Below are some key implications:

- Accept that virtually all Chinese cities will demographically decline between 2020 and 2065.

- Improve demographic forecasting and knowledge of demographic dynamics among planners and city officials. Provide incentives for local officials and planners to undertake city building within realistic demographic parameters.

- Address urban labor force shrinkage by extending the labor force participation and productivity of older demographic cohorts through public health measures and vocational retraining. 
- Plan and invest in urban infrastructure based on long-term population forecasts, not forecast peak population, to avoid "stranded" overbuilt infrastructure systems.

- Strengthen climate proofing of existing and planned urban infrastructure and maximize the use of new urban planning techniques, such as Low Impact Development and Transit Oriented Development (TOD) to develop green cities.

- Utilize smart city technologies, including fintech and Internet of Things (loT) in a selective customized manner to support urban efficiency.

- Over time, implement a distributed approach to urban services delivery that better reflects forecast intra-metropolitan population spatial distribution, particularly public services. The aim is to reduce the current centralized distribution of public services, such as health and education, particularly hightier and high-status services for smart cities. Such a measure will reduce transportation congestion and save time for residents.

- Develop and implement urban fiscal instruments at the city and at the cluster levels that are less dependent on demographic growth and are accountable in terms of impacts and cost-effectiveness.

- Regulate urban physical growth through growth boundary tools such as red-lining, agricultural land preservation, urban growth and/or service boundaries, and two-tier landscape instruments to avoid patchy development when urban population growth stagnates, and to protect land for agricultural, eco-system, and recreational uses.

\section{B. Shaping a More Rational Urban System}

\section{National Population Movement: Hukou, Caps, Dichotomous Property Structures}

The PRC's current urban system is the product of historical forces. In the early Communist period, the industrial base was focused in the northeast. "Third Front" industrialization ensued in 1964 in the West for strategic reasons. In the early 1980s, the "Open Cities" policy was implemented in the south to create a market socialist economy. The current Innovation Economy (more market driven) has been centered on a few key nodes, especially Shenzhen, in parallel with spatial equity policies to develop the central and west regions, while revitalizing the northeast.

The productivity of the PRC's urban system is constrained by a number of factors, primarily related to labor and talent mobility. The PRC lacks fully integrated labor markets. Its sub-optimal economic geography and urban system was acceptable when the PRC enjoyed global supremacy in mass manufacturing and matching specialized labor to employment was less important. However, the PRC is now moving toward a more innovative economy excelling in, or aspiring to, advanced manufacturing (4.0), digitalization, fintech, IoT, robotics, artificial intelligence (AI), autonomous vehicles, $5 \mathrm{G}$ communication systems and drones, and is encountering a more competitive hi-tech global economy. In this environment, the urban system needs to function more productively to unleash the talent that is key to innovation.

Constraints to labor mobility within and between urban clusters are particularly serious. Attracting talent to an urban region and retaining recent graduates (especially important in Wuhan, Nanjing, and Harbin) is as important, if not more so, than attracting firms. Equally importantly, such talent should be readily available to employers within the whole urban cluster.

Current constraints in the PRC to cross-jurisdictional access to pensions, health care, and other social benefits, in part attributable to the hukou system, impede labor market integration. The hukou system, although weakening in importance, and currently being liberalized in a number of ways, still can 
hinder recruitment of workers (particularly highly skilled technicians) to urban clusters, and even their movement within the cluster.

Hukou policy now cuts both ways. Cities such as Hangzhou, Tianjin and Wuhan use hukou issuance to attract talented individuals and deter lower skilled migrants. Satellite manufacturing cities such as Chongqing municipality use hukou issuance to attract factory workers. On the other hand, the PRC's superstar cities, particularly Beijing, issue an extremely limited number of hukou, numbering in the thousands annually, to prevent in-migration to the city. Hukou reform is a complicated issue. On the one hand, given the predicted decline in the PRC's urban population, even the superstar cities may regret having turned away potential residents. However, the spatially fragmented nature of social security programs makes local governments bear a high proportion of costs. Thus, a city like Beijing in granting hukou status to an individual (and his/her future household) may acquire over $\$ 125,000$ (approximately CNY865,000) in future financial obligations, but countering these costs will be gains in GDP growth, innovation, and shared taxes collected.

Perhaps the biggest benefit derived from effective urban cluster development worldwide is the creation of very large, efficient, and integrated labor markets; an example is the San Francisco centered Bay Region megapolis in the US. Should the PRC pursue urban cluster development primarily through physical infrastructure investment, while inhibiting development of efficient integrated labor markets, it will forego many of the potential benefits of urban cluster development. Furthermore, with hard infrastructure already in place, the case for giving priority to soft investment such as skills development and labor market efficiency improvements is even more compelling.

The PRC's development style is to introduce reform in subnational regions, then diffuse the concept if it proves successful. A highly developed urban cluster such as the Yangtze River Delta Cluster should therefore be considered as a locale to pioneer reforms related to health care, pensions, and hukou. In fact, in the Yangtze River Delta Cluster, some initial steps are already being taken such as crossjurisdictional validity of health coverage between Shanghai and some local jurisdictions in neighboring Jiangsu Province.

Implementation of the measures noted below may lead to increased spatial dis-equity in the urban system. But they will also lead to an overall improvement in the national Gini coefficient as people from poorer regions are able to access higher paying employment in high-performing urban clusters or supported by the new rural vitalization program. In other words, such measures would enable people prosperity to trump place prosperity, improving the national Gini coefficient.

To improve rational labor movement in the PRC, the following should be considered:

- The hukou system curbs rational labor movement to cities, particularly the most desirable and productive places, by limiting access to services. Accordingly, its eventual demise should be considered.

- Social benefits, particularly pensions and health insurance, should be nationally consistent and geographically portable. Otherwise, highly localized social benefits will continue to deter migration, contributing to lack of integrated national and urban cluster labor markets.

- Urban property, particularly residential property, can be owned through the leasehold system; however rural property is held collectively (although many informal means are used to enable quasi property rights in rural areas, especially near cities). This dualistic property rights model constrains outmigration from rural areas, including areas with low productivity agriculture and low standards or quality of life. 
- Beijing and Shanghai municipalities have established population caps. This could have the undesired result of discouraging talent from moving to these cities. As the urban population declines in the second half of this century, these cities may be clamoring for more population to retain their viability, as in the Tokyo region today.

- Regional development policy in the PRC is based on place prosperity, that is, supporting the economies of struggling cities and regions such as Harbin and Shenyang. Much higher returns on public investment could often be realized if the focus were on the education and health of people in the struggling regions and elsewhere. This would give them the option of staying and contributing to the revitalization of the urban region, albeit probably at a lower population level, or leaving to improve their standard of living and contribute to the development of cities and regions to which they move.

\section{Urban Clusters: Need Selective Focus, Each is Different}

The PRC's official 19 urban clusters contain over $29 \%$ of the PRC's land area, $82 \%$ of its population, and $90 \%$ of its economy. Thus, their planning and development is critical to the PRC's socio-economic and environmental future.

A single growth regime should not apply to all urban clusters. For example, the northeast clusters would benefit from more emphasis on high-value agriculture, world-class agro-industry, and tourism in tandem with accelerated out-migration and selective orderly de-industrialization, rather than an in-situ status quo development approach. On the other hand, the Greater Bay Region Cluster could be prioritized as the PRC's innovation hub, planned for rapid growth, and positioned to be one of world's leading innovation hubs on a par with Silicon Valley.

The national new urbanization policy calls for the urbanization of 100 million people in the western and interior regions. However, the urban demographic increment for all of the PRC between 2020 and 2030 is forecast to be 124 million people (see Table 1), and the attraction of east coast cities relative to interior, western, and northeast cities will continue, or even increase. Therefore, this target will be challenging to achieve and, if achieved, would represent a misallocation of resources. More realistic targets could be achieved by promoting a new type of urbanization that calls for issuing hukou to 100 million migrants and renovating urban villages and old/informal communities inhabited by 100 million people.

\section{Urban Clusters: Internal Effective Economic Development}

Within urban clusters, trying to equalize growth in all component geographic areas or settlements, and extend high-speed physical connectedness to all places, would generate significant economic inefficiencies and would be fiscally irresponsible. However, high speed internet and e-commerce delivery services (including by drones where appropriate) should be ubiquitously available. Certain localities within clusters would lose people, and this should be accepted. People oriented policies should be put in place in bypassed areas. These policies should emphasize vocational education aligned to the overall cluster's emerging economy or to the national economy, to promote socio-economic upward mobility through intra-cluster or inter-cluster migration or commuting.

Spatial planning at the regional scale (outside contiguously built up cities), should be efficient, based on corridors with nodes ("necklace" development). Selective and prioritized capital-intensive infrastructure such as expressways, HSR, and commuter trains need to reinforce such corridors to create synergy. Because of their cost, and the need for return on investment, they obviously cannot serve all areas within a cluster. Unavoidably, such infrastructure development will create spatial winners and losers within the urban cluster. 
Obviously, economic development cannot be master planned within the clusters, either sectorally or spatially; the market will and should play a strong role. However, indicative economic roles for localities within the cluster can be identified, based on thorough research and careful analysis of their comparative and competitive advantages, including access, and on cluster-level institutional processes. In sum, the goal should not be to achieve spatial economic balance but to maximize economic development and employment, environmental quality, and the welfare of the people currently living in the cluster.

Even across metropolitan areas within clusters, hard choices will need to be made. For example, in the Mid Yangtze River Cluster, a strong case can be made that Wuhan should be developed as the Central Hub city of the PRC, playing a role equivalent to Chicago in the US, or increasingly Dallas-Ft Worth. From a national point of view, benefits could be substantial. For example, Wuhan could become a central aviation and HSR hub. This would take pressure off Beijing and create an internationalized central city, opening up central the PRC to the world. It would leverage Wuhan's world's largest post-secondary student body in terms of retention and innovation. On the other hand, sharing high-end urban functions with Changsha and Nanchang could potentially dilute this role, with high costs to the Chinese national system. (As indicated by Figure 2, Changsha is one of the demographically slowest growing cities in the PRC, while Wuhan is one of the fastest growing of the interior region cities). It is obvious that intracluster indicative planning and investment choices will have implications for national development as well as within the cluster itself. In some cases, national interests should prevail over cluster scale interests.

The PRC urban clusters are not connected through commuter rail systems, which operate successfully in many urban clusters worldwide, such as New York, Chicago, Toronto, London, and Paris. The PRC's HSR system is creating major new suburban transport hubs (such as Shanghai Hongqiao), ${ }^{9}$ and connecting metropolitan places within urban clusters, but a commuter rail system could offer a middle tier of connectivity between the PRC's extensive HSR network serving regional and national scales, and the metro systems serving the metropolitan scale. Such commuter lines could reinforce corridor-oriented "necklace" type spatial development (the most energy and environmentally efficient development) between key nodes in urban clusters.

Below are some key implications:

- Within urban clusters, development of metropolitan and local areas should be facilitated based on their strengths and their comparative and competitive advantages.

- Given that cluster development will necessarily be somewhat uneven, vocational training should be in place to give residents the option to move within or outside the cluster; i.e. a people-oriented approach to cluster development should be implemented.

- Within urban clusters, regional connectivity infrastructure, adjusted for terrain, should be "necklace" form; that is, based on corridors containing the latest transportation modes and technologies and connecting key nodes, with higher density development around stations.

- A case can be made for regional scale commuter fast-comfortable-trains within clusters.

- No strong institutional and financial bodies that represent the cluster's overall interest and have borrowing capacity currently exist in the PRC, although permanent institutional bodies and processes related to urban cluster development have been established, particularly in the Yangtze River Delta Cluster. Thus, no group speaks on behalf of the interests of the clusters as a whole, as

9 Because the PRC's HSR system was developed recently, HSR stations tend to be in suburban areas, unlike in Japan and Europe, where the HSR systems were developed earlier. 
opposed to the priorities of individual local governments composing the cluster. Given the lack of a mature institutional structures to plan, budget for, and manage clusters, current cluster plans are primarily an amalgam of each component municipality's priorities. Under the current institutional framework, it is likely that the anticipated benefits of cluster development would be sub-optimal, if not negative. The national government would need to establish an institution representing each cluster, with the mandate to operate in the interests of the cluster as a whole for planning and development, including borrowing capacity, and to prioritize investment supporting the cluster's vision and strategic planning.

- Given the complexities of urban cluster development, the fast-changing development context facing Chinese cities, and the 15 to 20 year timeline needed to restructure urban systems, a 2040 time horizon for cluster plans is more realistic.

- The 19 urban clusters that have been identified are at very different stages of development. Accordingly, institutional and policy frameworks should vary. First, for areas that are truly becoming integrated, such as the Yangtze River Delta Cluster, cluster plans should optimize major social policy (spatially transferable pensions and health care) and trunk infrastructure (commuter rail systems) frameworks. Second, at the opposite end of the scale, policy packages that deal with a common problem such as rust belt dynamics in the proposed Harbin-Dalian cluster, but do not expect regional integration in the short to medium run, would be appropriate. A third set of clusters would be those that have the potential to substantially become more connected, but have not yet, such as the MidYangtze River Cluster or the Chengdu-Chongqing Cluster. In these cases, analysis should focus on better understanding regional (cluster) socio-economic and environmental spatial dynamics.

In all cases, local governments should deal with small scale localized interventions such as local street grids and land use. The emphasis at the cluster level should be on broad issues and policies such as regional-scale land use (particularly the built-up, arable, protected and/or environmental services land distinction), cluster scale trunk infrastructure, and structuring social programs to eventually operate cross-cluster. In other words, a structural planning approach should be undertaken.

\section{Shaping Future Metropolitan Structure}

\section{The "New Chinese City"}

Cities in the PRC, and elsewhere, will change dramatically over the next 10-20 years. The PRC's new urban economy, which is becoming more innovation, consumption, and advanced manufacturing driven (framed by "Made in PRC 2025" and "Design in PRC 2025"), will need different types of urban spaces than in the past. Chinese planners and property developers need to determine which new types of urban forms, and where, are needed to support PRC's economic restructuring. This would result in a better alignment between city building and rapid economic restructuring, and consequently higher productivity.

New work styles are dramatically reducing the need for office space; there is currently a large oversupply of Class A office space in the PRC, with many large cities having Class A office vacancies in excess of $30 \%$. At the same time, e-commerce is reducing the need for retail space. Chinese cities have significantly over-consumed land for manufacturing (relative to unit of economic output) for decades, partly because industrial land tends to be underpriced. More advanced manufacturing uses less land per unit of output and employment, overlapping spatially with service functions such as product design, software, and Al. At the same time, demand is increasing for third spaces where people can work together, as well as lifestyle spaces for entertainment, creative endeavors, and health. 
Demand for residential units will slow with the decline in the urban population, but there will be strong demand for higher quality housing in more livable neighborhoods. There will also be demand for a variety of housing types including micro apartments with communal facilities, more people friendly midrise housing, live-work spaces ("Soho" style), and active and assisted living seniors housing. As in the developed economies, the "living" component of cities will become relatively more important (further driven by "work at home" dynamics), consuming a larger proportion of the urban land area. Future Chinese cities will be more of a land use and activity kaleidoscope, rather than the current mosaic of homogenous land uses. (See Figure 5). Thus, the current land use control system and construction standards in the PRC, which were developed when land uses such as highly polluting industries and residential communities needed to be separated, is rapidly becoming obsolete. New modes of land use control such as form-based zoning, which is rapidly being introduced in North America and Europe, are needed. Shanghai is addressing this dilemma as it aims for more organic, mixed use, and human scale physical development (Shanghai Municipal Government, 2017). Leading metropolitan areas in the advanced urban clusters could be appropriate locales to introduce major reforms to the land control system. Shanghai and Shenzhen are currently trying to make such changes, but are constrained by outdated national land use control systems.

Figure 5: San Francisco Zoning Allows Kaleidoscope Structure: Multiple Uses in One Block
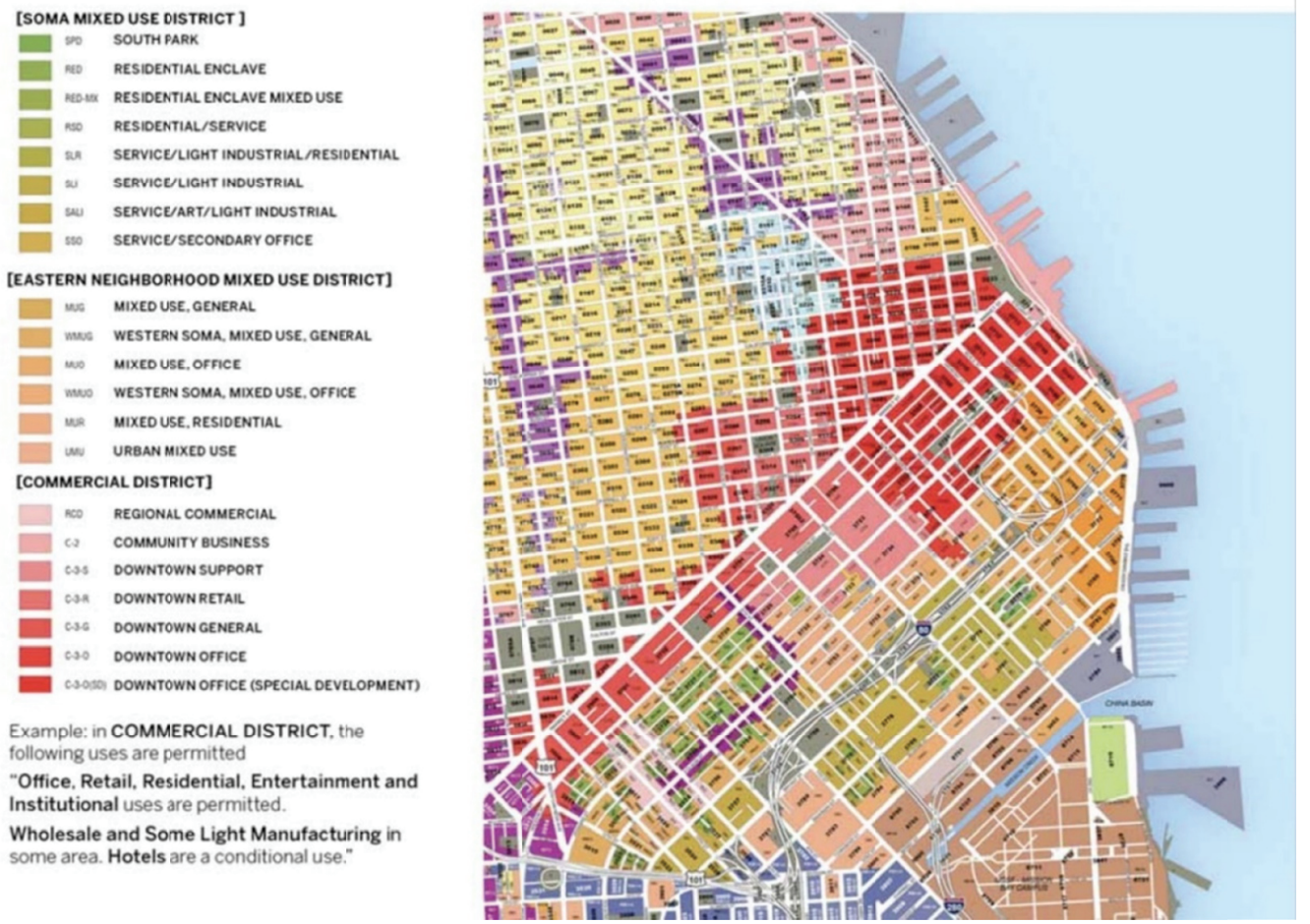

Source: San Francisco Planning Department, https://sfplanning.org/zoning (accessed 24 September 2019).

Since the 1980s, strong centrifugal forces dominated the PRC's metropolitan development, driven by manufacturing led urban economies. Factories were located in peri-urban belts, 25 to 100 or more kilometers from core cities in a patchwork of industrial zones and lands transitioning from rural to urban. These patterns are being replaced by stronger centripetal forces, as increased activity takes place in innovation zones, co-shared workspace complexes, and lifestyle districts. Lively, attractive, lifestyle districts will be very important, given the PRC's objective of achieving a more consumption driven 
economy. The PRC already is sprouting such districts; for example, Xintiandi and the K-11 Art Mall in Shanghai. However, there is much to learn from international experiences such as Icon Siam in Bangkok, South of Market in San Francisco, and Hudson Yards in New York. Investment in urban mass transit will support these centripetal and enable high core densities; This will be reinforced by shifts in consumer preferences as the middle-class grows and aspirations rise. It will also be reinforced by preferences, especially those of the millennial generation, for living and working in mixed-use environments. Overlaying all of the foregoing will be the introduction of autonomous vehicles, increased urban public transport, and enhanced connectivity, with significant benefits to Chinese cities.

The PRC faces several challenges in creating livable cities and facilitating innovation. Aside from the problem of homogenous zoning, floor area ratios (FARs) tend to be far too low, and lack spatial variation within cities. In the "New Chinese City" high levels of density near major transit intersections are needed to enable mixed use (horizontal and vertical) development within 1 kilometer radii of stations. This would facilitate walking, cycling, installation of people movers (such as moving sidewalks deployed in Macau, China or autonomous electric shuttles in dense areas), a mix of residences, shops, lifestyle areas (cinema, fitness, coffee shops), and health and education facilities. Since non-commuting trips to schools, medical services and leisure are growing faster than commuter trips, development of true TODs would lessen urban transit time, increase quality of life, and have a major positive impact on energy efficiency and green-house gas emissions. This in turn would bring significant environmental and socioeconomic co-benefits. Shanghai is one example that is making progress in this area.

Given that the national strategy is to increase the role of high-value innovative products in the country's economic output, Chinese cities need to create environments that facilitate innovation. Large industrial zones in peri-urban areas (Economic and Technology Development Zones) were appropriate and worldleading for the "factory of the world" development model. Suburban Hi-Tech Development Zones (such as in Chengdu, Hangzhou, Shanghai (Zhangjiang)) contributed much to early stage research and development in the PRC. The country has successfully transitioned from urban core factories (which were redeveloped as brown fields) to peri-urban economies, but there is a need for a further transition in industrial land use. International experience shows that the high-level innovation to which the PRC increasingly aspires demands new urban forms. This is because high-level innovation needs to attract the world's best talent; promote intensive human contact across firms, universities, and think tanks; and agglomerate millennials, who increasingly are the dominant innovation cohort with unrestricted digital access to information. International best practice includes places such as 22@Barcelona, Google New York, South of Market San Francisco, and Singapore One. Achieving such innovative spaces in the PRC will require flexible approaches to urban planning and development that respect mixed use. KIC in Shanghai is an example of a pioneering successful innovation space in the PRC.

Reflecting worldwide trends, affordable housing is an issue, especially in the PRC's most successful cities. Innovative means are needed to address this issue. A variety of instruments should be considered-from quotas for affordable housing in new developments (especially TODs, given the importance of transport to rank and file workers), to taxation to reduce high vacancy rates associated with speculation.

Next to central business districts, airports are the most important way to shape urban modules in Asian cities; they exert enormous economic force. Large new airports in Asian countries have resulted in locational shifts of two million or more people within the urban landscape. In the PRC, there are two issues in regard to airports and urban development. First, the aviation system is centered in Beijing, resulting in congestion, lost time and lost GDP, and sub-optimal urban economic diffusion effects. By contrast, the US has several major hubs such as Atlanta, Chicago, New York, and Los Angeles; Western Europe has London, Amsterdam, and Frankfurt; and Southeast Asia has Singapore and Bangkok. Second, land use around PRC airports is not optimized in terms of aerotropolis functions; that is, functions directly and indirectly related to aviation. Beijing's second major airport, Daxing, which was formally opened on 25 September 2019, could be a vital growth pole between Xiong'an and Beijing. 
Below are some key implications:

- If the PRC is to have efficient, highly livable cities, the structure of its cities will need to change, reflecting strong centripetal and mixed-use forces. This requires major changes in the administrative guidelines for city planning, as well as a review and revision of official standards for urban construction. At present, standards are often too high-for example, width of roads, and size of urban public squares-resulting in wasted land and/or super block grids.

- Local governments need to plan their cities based on mixed use, and higher and more variable FARs. This requires new tools such as form-based planning rather than homogenous mono use planning; and new concepts such as TODs, innovation districts, low impact development (such as, sponge cities and green cities), climate proofing of urban infrastructures, and loT. National guidelines will need to change to enable this initiative.

- The PRC needs to make its cities more walkable and human friendly by massively reducing the number and extent of barriers, particularly in TOD areas.

- In general, for land and transportation efficiency, cities should be expanded based on a contiguous fine grid; a finer grid would enable narrower arteries, which would be more human in scale and be less formidable as barriers. As indicated, between urban nodes, a corridor or node "necklace" form is the most efficient, with fine grids prevailing within nodes.

- The PRC is a leader in urban transportation; it needs to continue to innovate in areas such as autonomous and clean energy vehicles. The challenge is for land use innovation to keep pace with changes in transportation technologies.

- New urban development in the PRC, particularly near mass transit, should facilitate incorporation of affordable housing.

\section{Land Efficiency}

Appendix 4 provides basic metrics on built up land in the 19 urban clusters. In all cases, built up land per capita increased, although both built up land and change in built up land (2012-2016) metrics shows wide variation across clusters. Consistent with global trends, there appears to be a trend toward less urban land efficiency in the PRC. This is concerning given the limited amount of arable land (13\% of the PRC's land is arable according to the World Bank's arable land data base) and the high population concentration in the eastern part of the country (approximately $94 \%$ of the population occupies approximately $40 \%$ of the land area). ${ }^{10}$

The PRC's urbanization has generally been land supply-driven. Given the importance to local governments of fiscal revenue from land leasing, there is a strong incentive to over-release land. This results in land use scatter and lower population and floor space densities than would be ideal based on factors such as energy consumption, loss of agricultural land, traveling times, and economic criteria (for example, supply chain linkages and business and innovation transactions). Given declining urbanization rates, even greater care will need to be given to land release and development in the future. The PRC's cities proper are still commendably dense (often in the range of 7-10,000 persons per square kilometer), ${ }^{11}$ but peri-urban development often exhibits leap-frogging patterns, and even worse, occurs off key corridors in some cases. As future urban demographic and investment growth will be less available to correct such "errors", regional scale land use planning, particularly outside city propers needs to become more efficient.

10 Based on the Hu Huanyong Line, established in the 1930s.

11 The official national density guideline for cities is 10,000 persons per square kilometer. 
Urban land planning is also biased by the tendency of local governments to over-zone for high-rise Class A offices to create Manhattan-type skyscraper skylines; and to over-zone for industry, offices, and commercial land uses for tax (shared taxes) revenues. This approach fails to consider future trends of telecommuting, especially for residents living in the peri-urban areas with low TOD penetration.

As argued above, the rise of the PRC's new innovation and consumption economy will reduce demand significantly for conventional industrial land and office space, accentuating the land impacts of overall population trends. A higher proportion of cities' land and floor space areas will be for living - residential, leisure, innovation, and creativity. Innovation districts and TODs will, to some extent, replace more conventional industrial and office districts, taking into consideration telecommuting. At the same time, the proportionate amount of space devoted to transport may decline with autonomous vehicles, efficient transport, and less parking.

Given this ongoing and accelerating strong urban structural change, some existing policies need to be revisited. "New Areas", often massive in size as in Binhai (Tianjin) and Chongqing (Liangjiang New Area), will no longer be needed, at least at the presently allocated scale. A high-end economy will become less land consumptive and urban population growth will wane, making core city locations more important. Although Pudong is a success, other New Areas such as Binhai, and Liangjiang are struggling with land efficiency, economic returns on rural to urban land conversion, and business transactional efficiency (supply chain linkages, business / innovation / social interaction).

Although access to green space is important to urban quality of life, green space development needs to be undertaken in a thoughtful manner to improve access and support low impact development. Over the last 25 years, green space and blue space (artificial lakes in ETDZs) in the PRC has often been allocated in a wasteful manner, creating negative, rather than the intended positive, environmental and climate resilience impacts. In particular, green spaces are often in overly large rectangular parks, unconnected to green systems, and thus are significantly underused. ${ }^{12}$ Green space contributes the most to human well-being when it is part of a connected green system following ecological corridors, for example, along rivers. Such "long narrow" linear green systems maximize green space access for the urban population. They can extend unlimited distances out from cities, and offer multiple benefits including transportation (walking, bicycling), recreation (ranging from children's parks to tennis courts), drainage (for example, sponge areas and flood conduits), and biodiversity (ecological corridors). Chengdu is a leader in corridor green systems planning.

Below are several key implications:

- Industrial land should be priced at or closer to market rates. It has been, and continues to be, highly subsidized for economic development and local future taxation reasons (for example, shared corporate taxes).

- Municipalities should be urged to achieve the 10,000 persons per square kilometer standard over their whole built up territory. However, densities should be highly variable for land use efficiency reasons.

- At present FARs are highly uniform in Chinese cities, and too low in most cities. FARs should be highly variable to support population concentrations that would drive high transit ridership and enable TOD development.

- As the PRC leads the world in urban transit trackage, it should strongly encourage TOD development through higher FARs near stations (especially line intersections), changes in planning regulations to

12 Cities such as Bangkok have recognized this problem; formerly isolated Lumpini Park is now connected by an elevated pathway system (walking, biking) to other components of the green space system. 
encourage mixed development (horizontal and vertical), and use of public-private partnership (PPP) modalities with a focus on results and outcomes rather than inputs such as capital expenditure. TOD developments represent an opportunity for value capture associated with transit development. TOD development will result in much higher returns on public investment in urban transit.

- Planning mechanisms should allow and encourage horizontal and vertical mixed use, which is essential for high quality Innovation Zone, TOD, and lifestyle districts development.

- Urban plans should be based on realistic future population forecasts. At present, population forecasts are almost always too high, resulting in poor urban planning and unrealistic high demand for urban services and urban infrastructure that precludes the use of PPP modality.

- Urban plans should reflect market research on future demand for different types of land uses by amount of floor space. In the larger cities, good market research is available from domestic firms such as E House and multi-national firms such as Jones Lang LaSalle and Coldwell Banker Richard Ellis. Markets reflect changing urban functions and preferences, which need to be reflected in the mix of floor space on offer. More sensitivity to market research is needed in planning the overall release of land, and for zoning of individual types of land use, for example, land for Class A offices. This matching of urban planning to the mix of real demand for land and floor space is becoming much more important in the PRC as population and the economy slows, thus reducing the margin for error.

- Green space should be corridor in form to the greatest extent possible. The exception would be a very few flagship parks in a city, such as Central Park in New York, but even flagship parks should be connected to a networked green system.

\section{Pivoting to Quality Urban Regions}

Cities are built by a variety of stakeholders, including urban policy makers, planners, banks, property developers, and public and private sector corporate investors. The PRC has been extraordinarily successful over the last four decades in building world-class urban road and rail infrastructure, and more than enough housing; in fact, average sized housing units are larger than in Japan or Hong Kong, China. In sum, quantitative objectives related to city building have generally been reached. In some cases, there is oversupply, for example, too much housing in stagnant cities.

As a result, there is a general consensus that city building should now focus on the quality of urban systems. Quality encompasses a variety of themes including accessibility, walkability, urban barriers, community livability including availability of services and facilities, urban design, land efficiency, access to public space, construction quality, and energy efficiency of buildings.

However, in improving urban quality, the approach should not just be one of adopting best global practices, but also of providing the means to create the new cities that the PRC needs, as discussed in Section III.C.

\section{Community Livability}

The PRC has been a world leader in building cities for a historically unprecedented number of ruralurban migrants over the last four decades. Most people live in recently built housing units, which are large by East Asian standards, and mass transit is in place. Class A office buildings and state-of-the art industrial and science parks are found in abundance. In quantitative terms, the PRC's city building record in successful and unprecedented. The new challenge is to improve quality and livability, and to create the urban environments needed to support the new economy. 
Most Chinese residential communities built in cities over the last three decades are of modernist "tower in the park" design, with high-rise residential towers often laid out in rows and considerable open space among buildings.

Given the volume and pace of housing construction over the last four decades, a considerable percentage of buildings will need to undergo major retrofitting or be demolished and rebuilt over the next 20 years. Often the space between buildings is poorly used; for example, for car parks rather than services preferred by residents. Generally, these residential areas are fenced and gated. Large urban blocks bordered by massively wide super arterial roads create virtually impassable barriers to movement and inhibit walkable access to nearby facilities such as transit stops.

Higher ground coverage mid-rise building (approximately 8 stories) and green buildings using new energy efficient materials while reducing pollution could result in approximately the same densities as "tower in the park" high-rise neighborhoods, with a much higher quality of life. However, most residential communities continue to emphasize high-rises with poor energy efficiency.

This urban development/redevelopment model is based on entirely clearing areas, then building on these cleared spaces, resulting in the loss of local heritage and vegetation. With this approach, all buildings in a given area are of approximately the same age and, in many cases, of similar design.

Public facilities such as childcare and medical clinics, elderly care, day-to-day shopping, personal services, and handicap mobility access may not be integrated into the community. At the metropolitan scale, good schools and hospitals are likely to be located in the city center, reducing access to those (usually poorer) people living on the periphery.

Urban planners, urban designers, and developers are making in progress in developing higher quality, more organic communities. Shanghai now advocates organic community building and the end of largescale demolition.

Below are several key implications:

- Planners and developers should encourage more people friendly and compact mid-rise residential construction, with higher ground coverage.

- Organic development of communities with more retrofitting, infilling, and preservation of noteworthy cultural heritage and vegetation is needed as population growth declines and the demand for urban quality increases.

- Fencing and gating of large communities should be administratively discouraged; however, previous attempts to do this by the national government have run into opposition from neighborhoods concerned about security and neighborhood traffic.

- Finer road grids are needed with narrower, more human scale and easily crossable streets, incorporating walking and bike lanes.

- Social facilities and private stores and services should be located within neighborhoods to the greatest extent possible. At the metropolitan scale, over time, higher level services should be more evenly distributed to align with population distribution, rather than being concentrated in the urban core.

- Urban planning and design should occur within the context of the "New Chinese City" described earlier in this paper. For example, parking structures should be adaptable to other uses if not needed for vehicles, such as temporary flood storage as part of sponge city design (Barcelona, Spain and Bordeaux, France) as autonomous vehicles proliferate. 


\section{E. Urban Fiscal Sustainability}

A companion paper (Ahmad forthcoming) addresses fiscal issues facing the PRC over the medium-term period, including sub-national issues. Thus, the discussion below is selective and meant to complement that paper.

A growing body of analysis indicates that spending on infrastructure in Chinese cities is slowing, perhaps even peaking, although single digit growth in urban infrastructure investment over the medium term is probably the most likely scenario (The Economist 2018). This slowdown in fiscal spending is related to a growing regulation of debt, a crackdown on shadow banking by the national government, and slowing economic growth and urbanization.

There also appears to be a growing consensus in the national government that a larger percentage of spending should be on soft infrastructure, health, welfare, and pensions. This is because the PRC's cities and mega-urban regions generally have excellent physical infrastructure, so that marginal economic returns on additional physical infrastructure spending appear to be declining. As indicated by Figure 6 , fixed assets per person in the PRC are about the same as in Germany or Britain (International Monetary Fund; purchasing power parity calculation). This does not mean that there are no gaps in physical infrastructure in the PRC's metropolitan and urban cluster areas, but rather that future spending needs to be more selective. In terms of hard investments, a re-orientation toward the micro is needed. An example is the recent retrofitting of Pudong's connectivity to make the area more walkable and roads less intimidating to pedestrians.

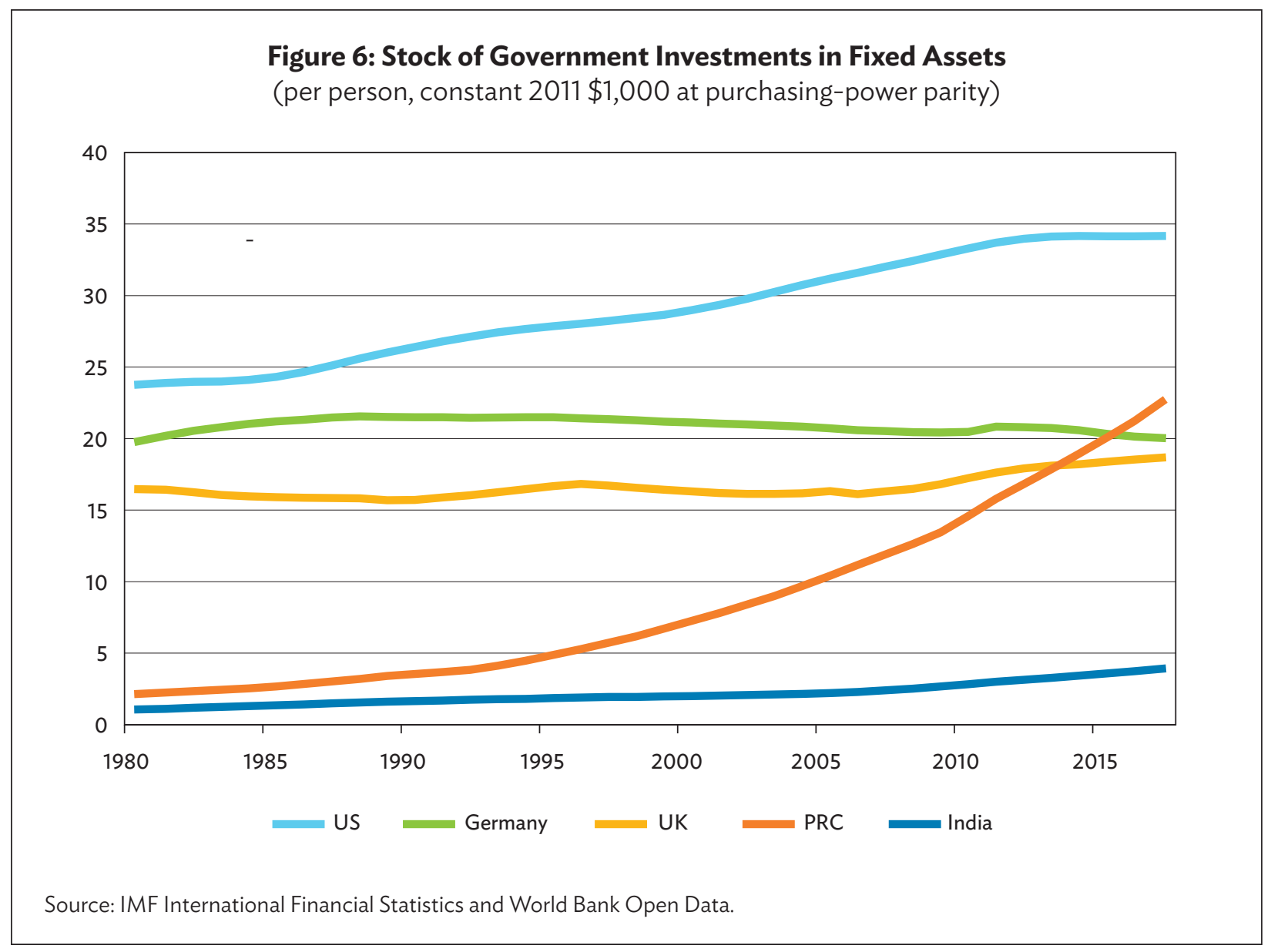


On the revenue side, the major fiscal problem facing the PRC's cities is their high dependence on land leasing revenues and, in some cities, innovative (but sometimes ill-considered) off-budget finance such as securitization of bridges and bonds issued by local financing facilities. There is a dearth of sustainable local revenue mechanisms; for example, property taxes and land value capture are currently untapped, but could potentially provide locally generated revenues. The current fiscal situation is likely to reach a crisis point with the expected slowing in demand for land (and possibly lower prices) by property developers. The PPP modality has potential for greater use in the PRC, at the project and neighborhood level.

The fact that municipalities generally over bound built up metropolitan areas, i.e., include vast rural areas, in the PRC is an asset in terms of managing a metropolis as a whole and planning expansion rationally, compared with highly jurisdictionally fragmented cities in places such as the eastern US. Nevertheless, financial incentives still need to be put in place to encourage cross jurisdictional cooperation, especially across municipal and provincial boundaries, even at the urban cluster level. In the US, the fastest growing type of government are "Special Districts". Special Districts involve several local governments undertaking one or more functions that need to be delivered across many jurisdictions ${ }^{13}$ such as water management, regional transportation, health care, and local economic development. The Greater Vancouver Regional District in Canada developed this way, starting with one function (water management) and evolving into a regional authority encompassing 23 city governments. Another mechanism used world-wide with success is matching grants; a senior government (national or provincial) offers a grant for a portion of the cost of a proposed project or program, for example, for a regional commuter rail system, but only on the condition that local governments will also contribute to the funding and co-operate in the planning and implementation. In the US, the Department of Transportation, with an annual budget close to $\$ 80$ billion, is influential in metropolitan and urban cluster planning. Before releasing funding (often matching grants) for regional scale urban systems, it requires a plan for the entire area, which forces inter-jurisdictional co-operation. In support of urban cluster development, many countries are now structuring data analysis and products around extended metropolitan and megapolitan areas. For example, the US Census compiles data for Standard Metropolitan Statistical Areas, which enable megapolitan data to be compiled quickly.

Below are several key implications:

- Hard infrastructure investment in the PRC's urban regions over the past 40 years has been high; city building is mature. The emphasis should turn to soft infrastructure investment such as portable pensions and health care insurance. Hard infrastructure should support development of "New Chinese Cities", for example, micro infrastructure supporting urban innovation or experiential economies; smart technology platforms in support of urban services delivery, including distributed smart services (water and power); circular economy systems (waste); and fintech.

- Current funding mechanisms for the PRC's cities are unsustainable, being too dependent on land leasing revenues and a variety of off-budget mechanisms. New sustainable mechanisms, such as property taxes, need to be formulated and implemented.

- To encourage cross-jurisdictional integrated investment in urban clusters, new mechanisms, which could benefit from international best practice, such as national matching grants and special districts, should be considered.

$\overline{13}$ For more information on Metropolitan and Megapolitan planning and implementation modes, see Webster et al. (2006). 


\section{OVERALL STRATEGY THRUSTS}

In sum, the PRC's national urban system, and its individual metropolitan areas and urban clusters will need to change radically over the next twenty years. This change will be driven by megatrends affecting demography, economic structure, and human preferences. A "New Chinese City" will be born, in parallel with similar dynamics elsewhere. The medium-term period will be critical in setting pathways to facilitate and accommodate such change.

Change is needed at two scales. At the national scale, a more rational integrated urban system is needed, especially in terms of human population flows and regional development approaches. The PRC would benefit substantially from national and urban cluster scale integrated labor markets, as talent becomes increasingly important in an innovation and high-level services economy. More integrated labor markets will unleash talent, the key to the PRC's economic future. Given the radical ongoing restructuring of the economy, the current "place prosperity" approach to development should be tempered with a greater emphasis on "people prosperity." Certain cities, urban clusters, and regions such as those in the northeast will inevitably decline in population and industrial terms. Others, like Shenzhen as an innovation center, and Sanya and Kunming, will boom, driven by amenity migration. Thus, there should be more emphasis on enabling the movement of people to where their talents can most effectively be used to contribute to the country, and to their own well-being.

At the urban community scale there needs to be a significant change in the way Chinese cities are designed and built. Fortunately, demographic pressures will be mild in most Chinese cities over the next several decades, enabling a shift to quality over quantity. Quality development should emphasize improved neighborhoods characterized by more people friendly mid-rise buildings with greater ground coverage, better placement of social facilities at the neighborhood and metropolitan scales, TOD development to conserve energy and human time, and more organic urban development and redevelopment incorporating heritage and eco-services functions. Cities in the PRC will look very different in the future than they do today. Very importantly, city building and urban form need to align better the PRC's fastchanging urban economies to facilitate innovation and productivity gains. To deal with megatrends, the horizon for urban planning should be 2035 or 2040, given that major urban structural reform generally takes $10-20$ years.

In conclusion, the PRC's future prosperity depends on facilitating development of a more rational national economic geography and cities where urban form and structures align with rapid changes in urban economies, demographics, technologies, and consumer preferences. 


\section{Appendix 1. Lead Urban Policies: 13th National Development Plan and New Urbanization Policy}

13th five-year plan period key urban policies:

- Relax the hukou system.

- Open prefecture level cities to skilled labor.

- Issue residence permits to those staying over 6 months.

- Accelerate the development of 19 urban clusters.

- Enhance the integration between regional core cities and their surroundings.

- Carefully relocate "non-core functions" of mega-cities.

- Enhance commuting systems connecting surrounding cities and towns.

- Accelerate industrial upgrading of large and mid-sized cities.

- Provide ample rental housing including people without hukou.

- Three "100 Million People Urbanization" Initiatives.

- Issue hukou to 100 million migrants.

- Renovate urban villages and old/informal communities inhabited by 100 million people.

- Urbanize 100 million people in central and western regions through migration to nearby cities and towns.

- Emphasize the development of mid and small-sized cities and specialized towns.

- Give country-level administration authority to large towns with populations of over 100,000.

Source: Compiled by authors from 13th National Development Plan and New Urbanization Policy (2014-2020). 
Appendix 2: Cluster Region Parameters (Population)

\begin{tabular}{|c|c|c|c|c|}
\hline Urban Cluster & $\begin{array}{c}\text { Population } 2012 \\
(' 00,000)\end{array}$ & $\begin{array}{c}\text { Population } 2016 \\
\left({ }^{\prime} 00,000\right)\end{array}$ & $\begin{array}{c}\text { Population } \\
\text { Change, } \\
2012-2016\end{array}$ & $\begin{array}{c}\text { Population Change, } \\
2012-2016 \\
(\%)\end{array}$ \\
\hline Beijing-Tianjin-Hebei & 10,770 & 11,205 & 435 & 4.04 \\
\hline Yangtze River Delta Cluster & 14,913 & 15,172 & 259 & 1.74 \\
\hline Pearl River Delta Cluster & 5,682 & 5,998 & 317 & 5.58 \\
\hline Harbin-Changchun Cluster & 4,820 & 4,690 & -129 & -2.69 \\
\hline South-central Liaoning Cluster & 2,823 & 2,819 & -4 & -0.14 \\
\hline Shandong Peninsula Cluster & 9,685 & 9,947 & 262 & 2.70 \\
\hline West-strait Cluster & 8,945 & 9,143 & 198 & 2.21 \\
\hline Hohhot-Baotou-Erdos-Yulin Cluster & 1,104 & 1,138 & 34 & 3.10 \\
\hline Central Shanxi Cluster & 754 & 769 & 15 & 1.99 \\
\hline Central Plain Cluster & 16,898 & 17,253 & 355 & 2.10 \\
\hline Mid Yangtze River Cluster & 12,593 & 12,879 & 286 & 2.27 \\
\hline Beibu Gulf Cluster & 4,017 & 4,144 & 127 & 3.17 \\
\hline Ningxia Yellow River Cluster & 521 & 553 & 32 & 6.16 \\
\hline Guanzhong Plain Cluster & 3,800 & 3,863 & 63 & 1.65 \\
\hline Lanzhou-xining Cluster & 1,146 & 1,239 & 92 & 8.06 \\
\hline Chengdu-Chongqing Cluster & 9,232 & 9,448 & 215 & 2.33 \\
\hline Central Guizhou Cluster & 1,579 & 1,629 & 50 & 3.18 \\
\hline Central Yunan Cluster & 2,053 & 2,102 & 49 & 2.39 \\
\hline Tianshan North Slope Cluster & 516 & 503 & -14 & -2.64 \\
\hline
\end{tabular}

Notes: The different colors refer to different yearly change in population from 2012 to 2016: yellow above 4\%; blue, 3 to 4\%; green, 0 to $3 \%$, and orange below $0 \%$.

Source: China City Statistical Yearbook. 


\section{Appendix 3: Cluster Region Parameters, Ranked by GDP per Capita}

\begin{tabular}{lcccc}
\hline & GDP per capita & $\begin{array}{c}\text { GDP 2012 } \\
(100 \text { million }\end{array}$ & $\begin{array}{c}\text { GDP 2016 } \\
(100 \text { million } \\
\text { Urban Cluster }\end{array}$ & $\begin{array}{c}\text { Annual GDP } \\
\text { Change } \\
(\%)\end{array}$ \\
\hline Hohhot-Baotou-Erdos-Yulin Cluster & 124,673 & 12,212 & 14,192 & 3.83 \\
Pearl River Delta Cluster & 111,572 & 47,294 & 66,926 & 9.07 \\
Yangtze River Delta Cluster & 97,980 & 107,342 & 148,656 & 8.48 \\
Tianshan North Slope Cluster & 92,543 & 4,039 & 4,653 & 3.60 \\
Shandong Peninsula Cluster & 67,576 & 50,884 & 67,215 & 7.21 \\
South-central Liaoning Cluster & 67,541 & 23,025 & 19,037 & -4.64 \\
Mid Yangtze River Cluster & 56,387 & 50,277 & 72,619 & 9.63 \\
Harbin-Changchun Cluster & 54,389 & 22,752 & 25,511 & 2.90 \\
Ningxia Yellow River Cluster & 52,687 & 1,577 & 2,913 & 16.57 \\
Central Shanxi Cluster & 52,601 & 3,297 & 4,047 & 5.25 \\
West-strait Cluster & 52,519 & 33,662 & 48,020 & 9.29 \\
Beijing-Tianjin-Hebei & 50,034 & 39,476 & 56,063 & 9.17 \\
Chengdu-Chongqing Cluster & 48,311 & 32,072 & 45,642 & 9.22 \\
Central Guizhou Cluster & 46,112 & 4,141 & 7,512 & 16.05 \\
Central Yunan Cluster & 44,453 & 6,759 & 9,343 & 8.43 \\
Guanzhong Plain Cluster & 42,611 & 11,747 & 16,460 & 8.80 \\
Beibu Gulf Cluster & 42,184 & 12,048 & 17,482 & 9.75 \\
Lanzhou-Xining Cluster & 38,636 & 3,057 & 4,786 & 11.85 \\
Central Plain Cluster & 37,684 & 48,680 & 65,017 & 7.50 \\
\hline Source: China City Statistical & & & & \\
\hline
\end{tabular}

Source: China City Statistical Yearbook. 


\section{Appendix 4: Cluster Region Parameters (Built-up Land)}

\begin{tabular}{|c|c|c|c|c|c|c|}
\hline Urban Cluster & $\begin{array}{c}\text { Built-Up } \\
\text { Land, 2012 } \\
\text { (1 sq.km) }\end{array}$ & $\begin{array}{c}\text { Built-Up } \\
\text { Land, 2016 } \\
\text { (1 sq.km) }\end{array}$ & $\begin{array}{l}\text { Built-Up } \\
\text { Land } \\
\text { Change, } \\
\text { 2012-2016 }\end{array}$ & $\begin{array}{c}\text { Built-Up } \\
\text { Land } \\
\text { Change, } \\
2012-2016 \\
(\%)\end{array}$ & $\begin{array}{c}\text { Built-Up } \\
\text { Land per } \\
\text { capita } \\
2012 \\
\end{array}$ & $\begin{array}{c}\text { Built-Up } \\
\text { Land per } \\
\text { capita per } \\
\text { capita } \\
2016 \\
\end{array}$ \\
\hline Beijing-Tianjin-Hebei & 3,667 & 4,466 & 799 & 21.78 & 34.1 & 39.9 \\
\hline Yangtze River Delta Cluster & 5,362 & 6,271 & 909 & 16.96 & 36.0 & 41.3 \\
\hline Pearl River Delta Cluster & 3,768 & 4,262 & 494 & 13.11 & 66.3 & 71.1 \\
\hline Harbin-Changchun Cluster & 4,154 & 4,628 & 474 & 11.41 & 86.2 & 98.7 \\
\hline South-central Liaoning Cluster & 1,835 & 2,276 & 441 & 24.01 & 65.0 & 80.8 \\
\hline Shandong Peninsula Cluster & 3,804 & 4,795 & 991 & 26.05 & 39.3 & 48.2 \\
\hline West-strait Cluster & 2,275 & 2,927 & 652 & 28.65 & 25.4 & 32.0 \\
\hline Hohhot-Baotou-Erdos-Yulin Cluster & 558 & 656 & 98 & 17.55 & 50.6 & 57.6 \\
\hline Central Shanxi Cluster & 394 & 454 & 60 & 15.21 & 52.2 & 59.0 \\
\hline Central Plain Cluster & 3,518 & 4,185 & 667 & 18.97 & 20.8 & 24.3 \\
\hline Mid Yangtze River Cluster & 3,616 & 4,359 & 744 & 20.57 & 28.7 & 33.9 \\
\hline Beibu Gulf Cluster & 1,156 & 1,393 & 238 & 20.56 & 28.8 & 33.6 \\
\hline Ningxia Yellow River Cluster & 363 & 407 & 44 & 12.10 & 69.7 & 73.6 \\
\hline Guanzhong Plain Cluster & 992 & 1,229 & 237 & 23.88 & 26.1 & 31.8 \\
\hline Lanzhou-xining Cluster & 375 & 560 & 184 & 49.15 & 32.7 & 45.2 \\
\hline Chengdu-Chongqing Cluster & 3,061 & 3,870 & 809 & 26.44 & 33.2 & 41.0 \\
\hline Central Guizhou Cluster & 470 & 674 & 204 & 43.40 & 29.7 & 41.3 \\
\hline Central Yunan Cluster & 540 & 679 & 139 & 25.75 & 26.3 & 32.3 \\
\hline Tianshan North Slope Cluster & 559 & 705 & 146 & 26.05 & 108.3 & 140.2 \\
\hline
\end{tabular}

Notes: The different colors refer to different yearly percentage change in built-up land from 2012 to 2016: yellow refers to growth above $25 \%$; blue, $20-25 \%$; and green, less than $20 \%$.

Source: China Urban-Rural Construction Statistical Yearbook 2012 and 2016. 


\section{REFERENCES}

Ahmad. E. Forthcoming. Financing High Quality Development in PRC. ADB East Asia Working Paper Series. Manila: Asian Development Bank.

China Statistics Press. China City Statistical Yearbook. http:/cdi.cnki.net/Titles/ SingleNJ?NJCode=N2018050234 (accessed on 24 September 2019).

The Economist. 2018. Is China's Infrastructure Boom Past Its Peak? September 20. pp 25-26.

The Economist. 2019. Once Again, China's Richest Region Is Pulling Ahead of The Others. June 8. pp 29-30.

Hanson, A. 2019. Ecological Civilization: Values, Actions, and Future Needs. ADB East Asia Working Paper Series. 21. Manila: Asian Development Bank.

International Monetary Fund. International Financial Statistics. http://data.imf.org/regular. aspx?key=61545853 (accessed on 24 September 2019).

Lee, R. 2019. Population Aging in PRC and Some Economic Consequences. ADB East Asia Working Paper Series. 17. Manila: Asian Development Bank.

Li, J, D. Webster, and J. Cai. 2018. Manufacturing-led Peri-Urbanization in Central PRC: The Case of Wuhan's Dongxihu District. International Development Planning Review. 40(2). pp 175-202.

National Bureau of Statistics. Annual Data. http://www.stats.gov.cn/english/Statisticaldata/AnnualData/ (accessed on 24 September 2019).

National Development and Reform Commission. 2016. The PRC'S 13 ${ }^{\text {th }}$ Five-Year Plan. Beijing: National Development and Reform Commission.

Oxford Economics. 2019. Global Cities Outlook. London: Oxford Economics.

Shanghai Municipal Government. 2017. Shanghai Master Plan 2017-2035: Striving for the Excellent Global City. Shanghai.

United Nations, Department of Economic and Social Affairs, Population Division. 2018. World Urbanization Prospects: The 2018 Revision, Online Edition. New York: United Nations.

Webster, D., C. Cai, and C. Maneepong. 2006. Metropolitan Governance in the PRC: Priorities for Action in the Context of Chinese Urban Dynamics and International Experience. Washington and Beijing: The World Bank.

Webster, D. et al. 2012. A First Glance at PRC's 2010 Census: Urbanization and Regional Dynamics. Beijing: Lincoln Institute.

Webster, D. et al. 2013. Urban Systems/Regional Development Policy Implications: PRC's 2010 Census. Beijing: Lincoln Institute. 
Webster, D., J. Cai, and L. Muller. 2014. The New Face of Peri-Urbanization in East Asia. Journal of Urban Affairs. 36(1).

World Bank. World Bank Open Data. https://data.worldbank.org/indicator/SP.POP.TOTL (accessed on 24 September 2019).

Yang, W. 2019. Towards a New Era of Ecological Progress. Keynote speech delivered at Tokyo Keizai University on January 26. 


\section{Not Business as Usual \\ Mega-Trends and the Need for New City Building Approaches in the People's Republic of China}

This paper assesses the urban features of the People's Republic of China (PRC) based on mega-trends such as the country's aging demography, a shift to more innovative and consumer-oriented urban economies, the growing preference of people to live in high amenity cities, and climate change. To address the implications of these mega-trends, urban development must respond to realistic demographic forecasting, focus more on quality development, and improve land use planning. These approaches can help the PRC achieve its ecological civilization goals via a more inclusive and low-carbon economy.

\section{About the Asian Development Bank}

ADB is committed to achieving a prosperous, inclusive, resilient, and sustainable Asia and the Pacific, while sustaining its efforts to eradicate extreme poverty. Established in 1966, it is owned by 68 members49 from the region. Its main instruments for helping its developing member countries are policy dialogue, loans, equity investments, guarantees, grants, and technical assistance. 